\title{
Assessing challenges of clinical education in a baccalaureate nursing program in Ghana
}

\author{
Mary Asirifi ${ }^{* 1}$, Linda Ogilvie ${ }^{1}$, Sylvia Barton ${ }^{2}$, Patience Aniteye ${ }^{3}$, Kent Stobart ${ }^{4}$, Olenka Bilash ${ }^{5}$, Cecilia Eliason ${ }^{3}$, \\ Gloria Ansong ${ }^{3}$, Lydia Aziato ${ }^{3}$, Atswei Kwashie ${ }^{3}$ \\ ${ }^{1}$ Faculty of Nursing, University of Alberta, Alberta, Canada \\ ${ }^{2}$ Faculty of Nursing, University of Northern British Columbia, British Columbia, Canada \\ ${ }^{3}$ School of Nursing and Midwifery, University of Ghana, Ghana \\ ${ }^{4}$ College of Medicine, University of Saskatchewan, Saskatchewan, Canada \\ ${ }^{5}$ Faculty of Education, University of Alberta, Alberta, Canada
}

Received: April 18, 2017

DOI: $10.5430 /$ jnep.v7n10p109
Accepted: May 3, 2017

Online Published: May 25, 2017

URL: https://doi.org/10.5430/jnep.v7n10p109

\begin{abstract}
Background: A 2010 study of preceptorship as a clinical teaching model in Ghana revealed weaknesses related to high student-preceptor ratios and inadequate support from faculty in the educational institution. A four-cycle community-based participatory action research study was designed to further delineate clinical teaching and learning issues and partner with Ghanaian stakeholders in critical analysis of possibilities for positive change in clinical nursing education. The purpose of this paper, taken from Cycle One of the study, is to provide understanding of the challenges of the current clinical teaching model(s) used in the study institution from the perspectives of students and faculty. Early engagement of external stakeholders is described. Methods: Each university target group was invited to complete a semi-structured questionnaire. Interviews were conducted with representatives from the Ministry of Health, the Nursing and Midwifery Council of Ghana, and the Ghana Registered Nurses' and Midwives' Association. Clinical documents were examined.

Results: Clinical teaching and learning issues identified included the need for: a) more effective clinical teaching and supervision; b) adequate equipment for practice; c) meaningful evaluation of performance; d) enhanced collaboration between the school and clinical settings; and, e) reduced travel time to clinical opportunities. External stakeholders became aware and supportive of the research endeavour.

Conclusions: Participants acknowledged changes are needed in order to improve clinical nursing education in Ghana. Clinical teaching and learning issues were identified and formed a baseline from which more in-depth discussion of resources, constraints and possibilities for change could ensue in subsequent cycles of the study.
\end{abstract}

Key Words: Clinical teaching, Community-based action research, Ghana

\section{INTRODUCTION}

Clinical teaching is a vital component of nursing education worldwide because student experience in the clinical setting connects theory to practice. Ideally, students are able to achieve quality practice and safety competencies in facili- tative learning environments established through collegial academic and practice partnerships. ${ }^{[1]}$ Setting the conditions for optimal student nurse clinical practice, however, remains challenging worldwide. Issues reported in the literature include: lack of close supervision of students by

*Correspondence: Mary Asirifi; Email: asirifi@ualberta.ca; Address: Faculty of Nursing, University of Alberta, Edmonton, Alberta, Canada. 
clinical staff due to nursing shortages and inadequate collaboration between clinical staff and academia; $;^{[2]}$ inadequate or scarce clinical placement sites, often as a consequence of increased numbers of students; ${ }^{[3,4]}$ reduction in traditional clinical placement opportunities related to health system changes $;{ }^{[4]}$ competition with other health disciplines for the same practice settings; ${ }^{[2-4]}$ shortages of academically qualified faculty members ${ }^{[2,5,6]}$ and, academic expectations that influence faculty workloads and make it difficult to hire and retain faculty with current clinical expertise or for faculty members to maintain their clinical expertise. ${ }^{[5-7]}$ Such issues are common globally but gain in intensity in more resourceconstrained national contexts such as Ghana.

There are few studies of clinical teaching in sub-Saharan Africa. A survey conducted in Cameroon revealed that clinical nurse educators lack opportunities to update their knowledge and skills, have few incentives, and often no formal clinical teaching guidelines. ${ }^{[8]}$ In Ghana nursing students receive clinical supervision from faculty, preceptors, charge nurses and staff nurses. ${ }^{[2]}$ Preceptors are the nurses/midwives designated to assume the primary clinical teaching/supervision responsibility for students assigned to their unit. The notion underlying the formal preparation of preceptors in Ghana was to create a liaison between hospitals and health educational institutions to facilitate the connection of theory to practice. Qualitative research to explore and gain insight into preceptorship from the perspectives of nursing students, preceptors, and nurse educators revealed that preceptorship was not well established and was not actualized or understood in ways described in the preceptorship literature. In addition, clinical teaching was influenced substantially by external stakeholders involved in nursing education. ${ }^{[2]}$ The external stakeholders are the policy makers of nursing such as the Nursing and Midwifery Council of Ghana (NMC) and the Ministry of Health (MOH), as well as the Ghana Registered Nurses' and Midwives' Association (GRNMA). In order to address the shortage of nurses, there was a policy to increase the intake of students in nursing schools by more than $200 \%$ between 2007 and 2011, ${ }^{[9]}$ with little increase in human and material resources allocated to nursing education. Supervision of students in the clinical setting, always a challenge, became more difficult. For example, one preceptor may supervise more than five students at a time while still carrying a full patient load. Inadequate preceptor support, lack of equipment in clinical settings (sometimes as basic as lack of blood pressure equipment), and inconsistencies in the evaluation process were challenging for the provision of optimal clinical education. To add to the challenge, laboratories for skill acquisition prior to entering the healthcare environment are poorly equipped in most schools of nurs- ing and access to simulation resources is rare. ${ }^{[2]}$ Thus, a four-cycle community-based participatory action research (CBPR) endeavour was launched in 2016 to further delineate clinical teaching/learning issues and collaborate with Ghanaian stakeholders to develop more effective clinical teaching strategies, tools and models. The purpose of this paper, taken from Cycle One of the study, is to understand the challenges, including strengths and weaknesses, of the current clinical teaching model(s) used in the study institution from the perspectives of students and faculty. Early engagement of external stakeholders, another aim of Cycle One, is described.

\section{METHOD}

The purpose of the study was to engage stakeholders in a research process that will ascertain the strengths and weaknesses of the current model(s) of clinical education in one undergraduate baccalaureate nursing program in Ghana; and offer strategies to enhance clinical teaching effectiveness that will meet or surpass national standards and are feasible within current and potential resources. A four-cycle CBPR approach was used to inform and guide this study.

Community-based participatory action research is a research approach that includes both the researcher and representatives from the participant group (community) in collaborative, egalitarian, and partnership processes to assess and problem solve an issue that, in ideal circumstances, is chosen by the community. ${ }^{[10-12]}$ Four faculty members at the Ghanaian School of Nursing, therefore, agreed to partner on a Collaborative Research Team to plan and respond to data collection as the research process unfolded. They reviewed the research proposal including the questionnaires and interview guides, provided feedback before the data collection instruments were finalized, and are participating in ongoing data analysis and interpretation, guiding any agreed upon changes, and participating in publications. CBPR also involves an iterative process of cycles of observation, reflection and action. ${ }^{[10-12]}$ Basic routines of CBPR are looking, thinking and acting. Looking (observation) involves gathering relevant information (data collection) and describing the situation. Thinking (reflection) involves analyzing the data and thinking about "What is happening in this situation?" This reflective process involves interpreting and explaining why and how things are as they are (theorizing). Acting in this context means planning, implementing and evaluating a change. ${ }^{[12]}$ These processes happen in a spiral manner and can mean working backwards through routines, repeating processes, revising procedures, rethinking interpretations and sometimes making radical changes in direction. ${ }^{[10-12]}$ 


\subsection{Focus on cycle one}

The intent of Cycle One of data collection was to gain a preliminary appreciation of how clinical practice experiences in nursing education are viewed by nursing students and faculty, as well as identify gaps in what is almost exclusively rich country literature, in order to revise the guiding questions for the subsequent cycle individual and focus group interviews if needed. The inclusion of student feedback is unusual in Ghana and was, therefore, an important aspect of this research. Nursing and Midwifery Council of Ghana (2), $\mathrm{MOH}$ (2) and GRNMA (2) representatives were interviewed as a strategy to inform those agencies of the research, enlist their support, and incorporate their perspectives and insights. Clinical practice documentation was examined. Feedback presentations following analysis of data kept stakeholders informed and provided opportunities to correct inaccuracies, seek clarification, and engage in conversation that could add more information or provide additional interpretive insight.

Convenience sampling was used to recruit 128 questionnaire respondents. Graduate students were included as participants as many of them are experienced nursing teachers. Collaborative Research Team members in Ghana recommended the distribution of hard copies of questionnaires instead of electronic data collection because of limited student access to computers. Completed questionnaires were returned in sealed envelopes. Participants and response rates included 79 (71\%) final year undergraduate students, 21 (16\%) nurse interns, $19(31 \%)$ graduate students, and $9(47 \%)$ faculty members. The low response rate from the nurse interns, who were in a required fifth clinical practice year, was because they were gaining experience in practice settings across Ghana. The nurse interns remaining in Accra were most accessible for participation in the study.

The content of questionnaires focused on positive and negative clinical teaching and learning experiences of students and faculty members, perceptions of strengths and weaknesses of clinical teaching/learning in Ghana, and suggestions for enhancing the effectiveness of clinical education. Content validity of the questions was ascertained by sharing the questionnaires with the $\mathrm{PhD}$ supervisory committee and the two examiners at the Candidacy Examination, the Ghanaian faculty in the Collaborative Research Team, and four graduate students in nursing who are from Ghana and engaged in study at the University of Alberta. University of Ghana masters-level students at the University of Alberta for a short academic practicum completed the questionnaires for faculty and graduate students and provided feedback regarding clarity and the time needed to respond. These activities constituted the pilot testing done before general distribution to potential respondents. Questionnaire items were similar for all target groups.

\subsection{Ethical considerations}

Participation was voluntary and consent was implied by completion of the questionnaire and through signed consent of interview participants.

\subsection{Analysis}

Simple content analysis was used to identify and categorize concepts from the open-ended questionnaire data. Content analysis is a research technique for analysing empirical text or data of an exploratory and descriptive nature, ${ }^{[13]}$ and involves examining the content of narrative data to determine prominent themes and patterns among the themes. ${ }^{[14]}$ Each questionnaire response was read and listed followed by categorization of strengths and weaknesses of current clinical education experiences, in order to identify salient issues and challenges. Recommendations for change were documented. Examples of responses were selected to illustrate what were reported as the most positive and most negative clinical teaching and learning experiences as students or as clinical teachers. Additional information and interpretive comments from the feedback sessions were incorporated and findings were shared with the Collaborative Research Team, in order to glean further perspectives related to the findings. Interviews with NMC, GRNMA, and MOH representatives were audio-taped and transcribed verbatim. Preliminary analysis related to the issues/challenges of clinical education in nursing was completed to get a sense of policy-maker and professional association perspectives. Further analysis of this interview data fits better with subsequent cycles of the project. Clinical practice documentation was reviewed for content and appraised for its comprehensiveness.

\section{RESULTS}

Results relate to the presentation of clinical practice documents examined, background of participants in relation to this study, stakeholder support for the need for changes in the current clinical teaching approach, issues/challenges related to clinical teaching and learning, and recommendations for effective clinical teaching in Ghana.

\subsection{Clinical education documents}

The clinical practice documents examined were: a) nursing school curriculum; b) clinical schedule books and log books developed by NMC; and, c) clinical performance and conduct form developed and used by the School of Nursing. The clinical documents revealed that clinical supervision is an expected standard for students at all levels of clinical education. The curriculum outlines clinical practice hours required for each specialty area in order to complete the nursing program. 
The NMC policies specify the minimum practice hours. Clinical evaluation documents developed by the NMC, such as clinical schedule books for undergraduate students and log books for nurse interns, were the focus of clinical evaluation of students. The clinical schedule book outlines clinical objectives and expected areas of competencies for nursing procedures to be accomplished through classroom teaching, demonstrations, and achievement of clinical proficiency at specific periods of time in the nursing program. Faculty clinical teachers and clinical staff who teach or supervise students on any of the nursing procedures outlined in the scheduled book sign when competencies are met. The log book contains clinical objectives, required nursing specialty areas, and hours required to complete clinical nursing practice in those specialty areas before becoming a Registered Nurse. In addition to the clinical schedule book used to evaluate students' clinical performance, the school of nursing also has an evaluation form to assess the clinical performance and conduct of students. The evaluation form consists of a rating scale of 1 (poor), 2 (fair) and 3 (satisfactory) to evaluate dress code/general appearance; punctuality; communication; relationships with seniors/colleagues; relationships with nurses, clients and families; general performance; initiative; and, reliability. Evaluation occurs at the end of each clinical rotation and may be completed by preceptors, staff nurses, charge nurses, or unit managers and is then sent to faculty clinical teachers at the School of Nursing. Thus, there is summative but no formative evaluation of student nurse clinical practice and much clinical evaluation responsibility is placed on clinical agency staff. Student involvement in the formal clinical evaluation is negligible and there is little focus on clinical knowledge or overall quality of care provided to patients.

\subsection{Sample characteristics}

Before presenting the content analysis of the questionnaire and stakeholder data, salient features of the sample are described. Of the 79 undergraduate student respondents, 27 had completed five to nine clinical placements while $52 \mathrm{had}$ experienced more than 10 clinical placements. Most of the students responded they had received clinical supervision and teaching from staff nurses, unit managers or charge nurses, preceptors and clinical faculty members. One of the students responded he or she had received clinical supervision from a medical doctor. Close to half of the students responded they had never received clinical teaching and supervision from a clinical faculty member and had not been mentored by a preceptor by the fourth year of their undergraduate program. Staff nurses remain very involved in the clinical education of undergraduate students. These data, when explored further, revealed a limitation of the study. Both generic undergraduate students and post-registered nurse students take very similar baccalaureate nursing programs and our data could come from either category of student. We neglected to ask the relevant question. It could be that the students with the fewest clinical rotations are the post-registered nurse students. Thus, there is some difficulty in the interpretation of results.

Nurse interns were asked how they felt about their readiness for the clinical expectations of the internship year. Post registration baccalaureate nursing students are not required to do the internship year. While 21 nurse interns returned questionnaires, only 20 responded to the question of preparation and only 18 specified the number of units on which they had gained the experience. Respondents reported a range of four to 12 months in the internship program. Most of nurses reported that they were very prepared while less than half stated that they were somewhat prepared. Respondents had received internship year experience on three to eight units at the time they completed the questionnaires and most, if not all, specialty units were named. It would be useful to have more detailed information from this group prior to moving forward with major changes in clinical teaching strategies and models. For example, what were the gaps in their preparation? What were the strengths? These findings cannot be interpreted without reference to the qualitative data from the questionnaires. Most of the nurse interns who reported that they were well prepared for their internship program indicated they prepared themselves psychologically about the realities of the clinical settings from the clinical experience they received from school and from part time nursing jobs. Most of the nurse interns responded that they were well prepared; however, they also indicated that more adequate preparation before clinical practice would have been helpful. The nurse interns who were somewhat prepared indicated that the lack of equipment both in the clinical settings and in the school posed challenges in relation to the development of clinical competencies required to meet internship clinical expectations. These nurse interns indicated that they received inadequate hands-on practice before the internship program.

The clinical experience and the teaching experience of both graduate student respondents and faculty respondents were captured. Of the 18 graduate students who responded to these questions (missing data from one student who answered the qualitative questions), a few had graduated from their first nursing program less than five years earlier whereas majority of the graduate students had been registered nurses from six to 20 years. Most of these students had less than five years since completion of the undergraduate degree program and a few of them reported six to ten years with a baccalaureate degree; so it can be assumed that most, if not all, of them were post-registered nurse baccalaureate graduates. All of 
the graduate students had more than five years of clinical experience with a range of six to 15 years. A few of the graduate student respondents had taught in schools of nursing and had taught clinically. The majority of the graduate nurses had been preceptors and all of them had guided students while they were staff nurses. Of the nine faculty members who responded, two were less than five years after graduation from their initial nursing education, with the years since graduation ranging from six to 20 years for the remaining respondents. Eight of the nine faculty member respondents had completed their undergraduate degrees more than 10 years earlier. A graduate degree is required for a faculty position. All faculty members reported at least six years of clinical practice experience, all had supervised/taught students when they were staff nurses, a few had preceptor experience, and the majority had taught clinically as part of their faculty position. It is clear that faculty and graduate student respondents had substantial numbers of years of experience in nursing practice as well as in clinical teaching.

\subsection{Perspectives on the current clinical teaching ap- proach in Ghana}

All participants, including the policy-makers and influential external stakeholders of nursing education in Ghana, supported the need for changes in the current clinical teaching approach in order to facilitate effective clinical teaching and supervision in Ghana. Themes emerging from the data describe the need for: a) effective clinical supervision and teaching for patient safety and to build students' competencies; b) adequate equipment for clinical teaching and learning; c) meaningful evaluation of students' performance; d) positive clinical teaching environments; e) collaboration between school and clinical settings; and f) reduced travel time to clinical practice opportunities.

\subsubsection{Stakeholder support}

Support from external stakeholders for change and for the study was enthusiastic and demonstrated their awareness of deficiencies in the current models of clinical practice in nursing education. Comments from NMC, GRNMA, and MOH representatives included:

\section{Support}

"I want Ghana to attain the high education standard like any other country. I do not want the standard of nursing education in Ghana to be dropping so if there are any changes through a research-based project I will support it" (GRNMA).

\section{Awareness of the need for change}

"Yes, we need a change and the change will work. What I will encourage you to do is to get the clinical nurses involved in coming out with a model that will fit the Ghanaian system of nursing education. If the policy makers support it, I believe we will all benefit from it." (NMC)

\section{Readiness to act}

"At the MOH level, policy is influenced by evidence-based practice. We are ready to influence change and if we are able to present our case which is evidence-based like yours then it will be easier to use in policy making." $(\mathrm{MOH})$

Thus, a key component of CBPR, gaining decision-maker and influential stakeholder awareness and support, was achieved in Phase One of the project.

\subsubsection{Effective clinical supervision for patient safety and to build students' competencies}

Participants indicated that effective clinical supervision and teaching is needed for patient safety and to build students' competencies in relation to: a) high quality and sufficient hands on practice opportunities; b) psychomotor skills; c) communication skills; d) integration of knowledge into practice; e) evidence-based practice; and f) opportunities for varied clinical experiences. While aware that attention to the above-mentioned components is critical for effective clinical teaching, participants acknowledged deficits in current clinical teaching models and practices. Comments revealed that opportunities for hands-on practice or for direct supervision by a clinical faculty member were rare but valued and included some interesting key words and phrases. The most salient ones are presented. Positive experiences made students feel valued, confident and supported. They presented challenging learning opportunities.

Valued and confident: One of the undergraduate student nurses indicated that "I felt valued and confident when I was allowed to perform wound dressing under aseptic technique successfully."

Supported: Another undergraduate student indicated that "Having my lecturers come around to work directly with me and take me through some of the procedures in the unit made me feel supported."

Challenging clinical experiences: One nurse intern explained that "I detected that my patient's blood pressure was very high and his condition was critical. I immediately informed the charge nurse. The physician was contacted as well and we gave appropriate treatment and the patient was saved. I feel happy that I was able to apply my nursing skills to save a life." 
Experienced teachers found satisfaction in the clinical teaching role when they were able to engage students in meaningful learning moments and promote learning in a real-life situation. Graduate students and faculty with clinical teaching experience also expressed satisfaction with clinical teaching roles when they were able to:

Engage students in meaningful learning moments: "As a lecturer and a clinical teacher, I was glad and satisfied that I engaged my students in a hands-on practical session and it was very successful because the students enjoyed the learning session."

Promote student learning in a real-life situation: One of the graduate students explained that "When I have to teach students skills acquisition on the wards/units after the student has been taught in the classroom, I feel so motivated and encouraged when the student nurse is able to return the skills taught on real patients at the clinical settings."

Respondents expressed frustration in relation to inadequate clinical equipment, meaningless evaluation practices, lack of student input into clinical evaluations, clinical environments not conducive to teaching and learning, insufficient collaboration between academic and clinical settings, and excessive travel time/barriers interfering with time available for clinical practice.

\subsubsection{Inadequate equipment}

Most of the participants indicated that inadequate equipment both in the school and clinical practice settings is a huge barrier to effective clinical teaching and learning in Ghana. In order to support student learning, some clinical settings demand that students provide their own items such as thermometers, gloves, stethoscope, and hand towels in order to engage in hands-on opportunities. These items impose financial constraints on student learning. Participants shared their frustration of providing care with limited equipment. As one nurse intern said: "We lack clinical teaching and learning equipment to practice with both in the skills lab and in the wards". An undergraduate student reported that "The unavailability of disposable gloves on the wards made it difficult for me to practice. Also, the disposable gloves were hoarded from us (students) in the unit, creating unavailability of gloves to work with."

\subsubsection{Meaningless evaluation}

Students are evaluated by staff nurses, nurse preceptors, charge nurses, and unit managers. The clinical schedule books (undergraduate students) and the log books (nurse interns) provided by the Nursing and Midwifery Council of
Ghana are the focus of students' evaluations. The schedule books and the log books have components of nursing procedures that students are supposed to complete at a specific period of time during their clinical practice. The intent is that clinical teachers (nurse preceptor, staff nurse, charge nurse, or nurse manager) sign off students on the procedure after the students perform activities under their supervision. Thus, evaluation is driven by psychomotor skill in procedures and not by quality of patient care provided. Participants shared their concerns about how students are evaluated during clinical practice.

Students not involved in evaluation: An undergraduate student reported that "Sometimes our clinical performances are evaluated by nurses with whom we have not worked. We are not involved in our evaluation performances."

Lack of evaluation: A nurse intern described how ineffective clinical supervision could have negative effects on students' evaluations: "Sometimes we practice with no supervision and our clinical performances were not evaluated at the end of the clinical practice."

Lack of agency/academic collaboration: A faculty member suggested that: "We need to provide support for the clinical teachers to evaluate students' performances effectively. It is important for us to discuss with the clinical teachers how we expect them to evaluate our students' performances."

\subsubsection{Environments not conducive to teaching and learn- ing}

Most participants indicated that there is the need for good interpersonal relationships between students and staff nurses for positive clinical experiences to occur. One of the undergraduate nurses reported that "I will never forget my first day in the medical ward in my first year. A nurse said to me: you are a degree nurse and you don't know how to check vital signs. Diploma nurses are even better off. I nearly got discouraged if I had not received reassurance from mates." Another student added that "regardless of where we are coming from in terms of academic background, the staff nurses on the ward should be willing to involve us, delegate and supervise us where necessary." Not all students blamed clinical staff as they revealed that students' attitudes towards clinical practice could have negative impacts on their learning. Some students have habitual truancy and deliberately miss important learning opportunities during clinical rotations. This is possible because of lack of staff or clinical faculty time to always attend to whether a student is actually present in the clinical setting. This raises the question as to whether all students truly meet the NMC standards for clinical practice. 


\subsubsection{Insufficient collaboration between academic and clinical settings}

A lack of collaboration between schools and clinical settings constrains effective communication and affects vital components of clinical teaching and learning. Furthermore, participants indicated that learning similar ways of performing procedures in the classroom and the clinical setting would make it easier for students to integrate and apply theoretical knowledge. Inconsistencies were common. A graduate student with teaching experience indicated that: "As a tutor, $I$ feel sad when I visit the clinical sites of my students and find them doing the wrong procedure after having been taught the right thing in the classroom and the skills laboratory. It makes me feel like a failure that I could not bring a change in my students for them to copy the wrong practice on the wards."

\subsubsection{Excessive travel time for clinical practice opportuni- ties}

Most of the students indicated that the school bus takes them to the clinical settings but that busy and slow road traffic keeps them stuck in the traffic for hours. Usually students are late. In addition, in order to avoid the traffic, the school bus picks them up early to return to campus. As an undergraduate student stated, "The school bus usually comes to pick us up while we are still working in the units. This causes us to hurry and finish our nursing procedures and we miss the opportunity to perform handing over and taking over of procedures." Thus, even the mandated hours of clinical practice experience are seldom met even by conscientious students.

\subsection{Recommendations}

What the positive and negative comments about the quality of student clinical practice, the clinical documentary evidence, and the external stakeholder comments reveal is important. There is awareness of the critical issues, there are faculty members who express satisfaction when positive clinical teaching occurs, students appear eager for better quality clinical opportunities, and external stakeholders, including policy-makers, seem receptive to change. What then did they recommend?

Most participants gave recommendations to enhance clinical teaching and learning in nursing education. They suggested adequate time for clinical teaching, restructuring of clinical teaching approaches, need for more clinical teachers, and increased hands-on practice opportunities. Some of the barriers and resource constraints were revealed in the recommendations.

Participants indicated that faculty clinical teachers and clini- cal agency staff assuming teaching responsibility need adequate designated work time or other incentives for effective clinical teaching to occur. The clinical faculty member may be teaching in more than one clinical setting on the same day and traffic issues make it challenging, perhaps impossible, to get to all practice settings on a regular basis. Also, staff nurses, preceptors and managers in clinical settings maintain their normal roles while teaching students and role conflict with competing priorities may occur. Thus, it was recommended that: "The workload of the faculty members responsible for clinical teaching should be reduced in order to have enough time for clinical supervision and teaching."

Participants believe that re-structuring of the current teaching approach and acquiring more clinical faculty members in Ghana will enhance clinical teaching and learning to facilitate students' confidence in clinical practice. A faculty member indicated that: "I believe that clinical teaching and learning is important in the undergraduate program. It should be structured in such a way that would benefit the student to build their confidence to work without intimidation and fear." This comment about intimidation and fear is critical and an example of a recommendation yielding perhaps unintentional additional data. It may be an indicator of student-teacher hierarchy and relationship or clinical setting hierarchies. In addition, in order to make clinical teaching more effective, there should be recruitment of more faculty clinical teachers to meet the learning needs of the high numbers of students. "If we recruit more clinical teachers and involve the clinical staff to assist with supervision of the high numbers of students who visit the clinical settings, I think clinical teaching in the nursing program will be effective”. There is a sense that students will gain clinical competence and confidence in nursing practice if they are given the opportunity for frequent hands-on practice in the school laboratories and the clinical settings. How can these recommendations be expanded and met with the resources available? These recommendations are common in all nursing education contexts but what would make them feasible in Ghana or are other solutions needed? Let us now turn to a discussion of the findings.

\section{DiscuSSION}

Results suggest that there is consensus within the nursing community in Ghana that changes are needed to enhance the effectiveness of clinical teaching in nursing education. Questionnaire and external stakeholder responses indicate that there is support and readiness for change. There was much congruence in responses of all target groups in the sample as to the major challenges to be addressed. Therefore, what is needed to move forward? A basic understanding of change theory is one need within the Collaborative Research Team 
and the decision-makers internal and external to the School of Nursing. Agreeing on the change theory to use can be a first step. Exploring possibilities from what is done in other contexts is another necessary step and thus became the focus of Cycle Two of the research. The challenges revealed by participants, with the exception perhaps of excessive travel barriers, mirror those in the research literature on clinical teaching in nursing. The resources needed to resolve them may, however, be less available.

Kotter's eight stage theory of organizational change ${ }^{[15]}$ is a promising approach that is congruent with the use of CBPR. The first step is creating a sense of urgency and seizing or creating a significant opportunity to sensitize people to get involved in change. ${ }^{[15]}$ Stakeholders of nursing education expressed concern that clinical nursing standards in Ghana were dropping and attributed it to increased student nurse numbers. There was agreement that changes in clinical education in schools of nursing are needed. CBPR provided an opportunity to achieve Kotter's second stage of change, which is building a coalition. Building a coalition was achieved through creation of a Collaborative Research Team and engagement of multiple stakeholders in the research process through gaining their perspectives as research participants and, providing subsequent feedback sessions to present Cycle One findings.

The high student/clinical teacher ratio is related to the proliferation of new nursing schools and increased student intakes as government policy was implemented to curb the shortage of nurses. ${ }^{[2,9]}$ Growth in student nurse numbers occurred without increases in resources such as faculty, physical infrastructures, or clinical teaching equipment. Consequently, student numbers exceed classroom, library, clinical skills laboratory, and clinical agency capacity for students in many places. ${ }^{[16]}$ Studies have shown that the dual function or heavy patient care workload of staff nurses and other clinical agency personnel who also assume educational responsibility for students reduces the time needed for effective student supervision. Students may be expected to handle challenging clinical situations alone ${ }^{[2,17,18]}$ or, as our data reveal, miss learning opportunities and be relegated to observer roles. Ideally, in order to ensure effective clinical supervision in nursing education in Ghana: a) the workload of nursing clinical teachers both in the school and clinical settings should be reduced; b) over crowding of students at the clinical settings should be minimized by negotiations between the schools and clinical settings for appropriate times for clinical placements; c) there should be adequate support for clinical teachers, both faculty and clinical agency staff, through collaboratively planned educational workshops and seminars, as well as verbal or monetary incentives for those who accept educational responsibility; e) more faculty clinical teachers should be recruited for full time, part-time, secondments, and adjunct positions; and, f) undergraduate or graduate students who have interest in clinical teaching should be encouraged, employed and mentored as part of their graduate program. Unfortunately, most of these suggestions require additional resources that are unlikely to be forthcoming in amounts that would meet all recommendations. Thus, creativity in designing solutions and ranking of priorities are critical. Again, the CBPR approach facilitates the generation of possibilities and the setting of priorities and next steps.

Results also revealed the need for high quality and sufficient hands-on practice opportunities for students to develop psychomotor and communication skills, integrate knowledge, and engage in evidence-based practice. Well prepared clinical teachers, whether faculty or clinical agency staff, are required to expose students to challenging direct patient care opportunities in order to develop their professional clinical competencies. ${ }^{[19]}$ Effective clinical teachers stimulate students to integrate evidence-based theoretical knowledge into high quality, safe patient care. ${ }^{[20]}$ Learning about researchbased pedagogy motivates clinical teachers to use innovative teaching strategies to achieve the goals of clinical education. ${ }^{[21]}$ To achieve educational goals, students and faculty members require adequate library skills to search and retrieve recent, relevant, and accurate evidence. ${ }^{[22]}$ Access to computers, high speed internet, and data bases are priorities for both faculty and students. Clinical evaluation tools and processes were a major concern of students and faculty. Studies have shown that prompt constructive feedback, allowing students to construct learning objectives, and involving them in clinical evaluation are important for learning. ${ }^{[23,24]}$ Participants of this study suggested that clinical evaluation reform may be a priority for which consensus may be achieved fairly easily. Participants indicated the need for more collaboration between schools and clinical settings. Such collaboration could increase access to resources, reciprocity of roles in the clinical education of students, and facilitation of clinical environments more conducive to teaching and learning. ${ }^{[22]}$ Success with this strategy would enhance students' clinical learning and better prepare them for the internship year. Opportunities for paid undergraduate student nurse clinical work experience was found to positively shape the post-registration experience of newly graduated registered nurses in Hong Kong. While the researchers cautioned that employed nursing students still needed sufficient supervision, the support and time that senior nurses provided to the employed undergraduate student nurses for their further development into competent nurses were taken for granted 
without complaint when students were perceived as helpers rather than learners. ${ }^{[25]}$ Close clinical agency and academic institution relationships could foster such student opportunities and resolve not only educational issues but also decrease challenges related to staff shortages and students' inability to provide some of their own equipment/supplies when in educational clinical rotations.

A stressful clinical teaching and learning environment increases students' anxiety and can interfere with their clinical learning. ${ }^{[22,23]}$ Stronger interagency collaboration and reciprocity, as well as attention to interpersonal relationships between students and clinical agency staff, clinical agency staff and clinical faculty members, and students and clinical faculty members can promote student-friendly clinical environments. Also, student behaviours, such as truancy and missing clinical practice without notifying clinical teachers, is inappropriate and do not suggest high motivation to become good nurses. More collaboration, clear clinical objectives, and supportive clinical teaching and learning environments would improve students' learning outcomes in relation to critical thinking skills, clinical competencies, interpersonal communication, self-confidence, and willingness to ask questions. ${ }^{[24,26-29]}$

While issues identified as challenging for effective clinical supervision in Ghana were similar to those in the literature, the intensity of challenges appears to exceed what is reported in more economically advantaged countries. What was not found in the literature was the need for reduced travel time for students to get to the clinical practice settings. Most students live on the university campus and take school buses to clinical agencies. Delays in traffic are expected and can decrease student punctuality and lead to pick-up times earlier than is optimal. Students can miss important patient care activities. One solution is to schedule student clinical rotations in nearby facilities as much as possible. An ultra-modern well-equipped hospital on the university campus where this study was conducted is currently under construction. A decision was made that no students will receive clinical education in that facility. An opportunity for enhanced clinical education of nurses and other health professionals seems be lost. Proactive lobbying with policy decision makers could focus

\section{REFERENCES}

[1] McKown T, McKown L, Webb S. Using Quality and Safety Education for Nurses to Guide Clinical Teaching on a New Dedicated Education Unit. Journal of Nursing Education. 2011; 50(12): 706-710.

[2] Asirifi A, Mill J, Myrick F, et al. Preceptorship in the Ghanaian context: "Coaching for a winning team". Journal of Nursing Education on the potential for the presence of students to enhance the quality of patient care, the possibilities for engagement in clinical and health professional educational research, and the opportunities for innovation and creativity in designing new models for clinical practice in nursing and other health professional education. An excellent example would be the development of a model of inter-professional education that could enhance care through better collaboration across health disciplines in health care settings. ${ }^{[30-34]}$

\section{Conclusion}

This CBPR project highlights challenges to effective clinical teaching and learning in nursing education in Ghana. It is apparent that there is potential for improvement. Cycle One of this CBPR project revealed the challenges, created awareness, and generated support for change. In Cycles Two and Three data collection was expanded to include focus groups with clinical agency nursing staff and graduate students, in-depth interviews with faculty members, and presentation of clinical teaching models incorporating relevant research literature of clinical teaching approaches used in other national contexts. Cycle One succeeded in providing the base from which action to create more effective clinical nursing education could begin. The questionnaire data provided baseline data from which further data collection could focus on approaches and solutions for enhancing clinical nursing education in the future, as well as uncover the complexities within the Ghanaian context that could make meaningful change difficult.

\section{ACKNOWLEDgements}

The first author would like to thank her supervisory committee members for their incredible academic support and guidance in her $\mathrm{PhD}$ program. Also, the first author is grateful to the Faculty of Graduate and Research Studies and the Graduate Student Association of the University of Alberta for providing funding to travel to Ghana for data collection. Another thank you goes to the Research Collaborative Team and the School of Nursing at the University of Ghana, and all participants for their effort and enthusiasm and welcoming spirit to share their experiences of clinical teaching.

\section{CONFlicts OF InTEREST Disclosure}

The authors declare that there is no conflict of interest. and Practice. 2013; 3(12): 168-176. https://doi.org/10.5430/ jnep.v3n12p168

[3] Brunero S, Lamont $\mathrm{S}$. The process, logistics and challenges of implementing clinical supervision in a generalist tertiary referral hospital. Scandinavian Journal of Caring Sciences. 2012; 26(1): 186-193. PMid:21883342 https://doi.org/10.1111/j.1471-6712.20 
$11.00913 . \mathrm{x}$

[4] Gardner SS. From Learning to Teaching Effectiveness: Nurse Educators Describe Their Experiences. Nursing Education Perspectives. 2014; 35(2): 106-111. https://doi.org/10.5480/12-821.1

[5] Jamshidi N, Molazem Z, Sharif F, et al. The Challenges of Nursing Students in the Clinical Learning Environment: A Qualitative Study. Scientific World. 2016; 1-7 p.

[6] Johanpour F, Azodi P, Azodi F, et al. Barriers to Practical Learning in the Field: A Qualitative Study of Iranian Nursing Students' Experiences. Nursing and Midwifery Studies. 2016; 5(2): 1-3.

[7] Maguire DJ, Zambroski CH, Cadena SV. Using a clinical collaborative model for nursing education: application for clinical teaching. Nurse Educator. 2012; 37(2): 80-85. PMid:22327534 https ://doi.org/10.1097/NNE.0b013e3182461bb6

[8] Eta VE, Atanga MB, Atashili J, et al. Nurses and challenges faced as clinical educators: a survey of a group of nurses in Cameroon. The Pan African Medical Journal. 2011; 8: 28.

[9] WHO \& Global Workforce Alliance. Ghana: Implementing a National Human Resources for Health Plan Global Health Workforce Alliance, World Health Organization, Case study. 2008. Available from: http://www.who.int/workforcealliance/know ledge/case_studies/CS_Ghana_web_en.pdf?ua=1

[10] Caine V, Mill J. Essentials of Community-based Research. California: Left Coast Press Inc, 2016.

[11] Minkler M. Using Participatory Action Research to Build Healthy Communities. Public Health Reports. 2000; 115: 191-197. Available from: https://www.ncbi.nlm.nih.gov/pmc/articles/PMC1 308710/pdf/pubhealthrep00022-0089.pdf

[12] Stringer ET. Action research. (3rd ed.). Los Angeles: Sage Publications; 2007.

[13] Dannapfel P, Nilsen P. Evidence-Based Physiotherapy Culture - The Influence of Health Care Leaders in Sweden. Open Journal of Leadership. 2016; 5: 51-69. http://doi.org/10.4236/oj1.2016.5 3006

[14] Loiselle CG, Profetto-McGrath J, Polit DF, et al. Canadian Essentials of Nursing Research. Second Edition. New York: Lippincott; 2007.

[15] Lachman P, Runnacles J, Dudley J. Equipped: overcoming barriers to change to improve quality of care (theories of change). Arch Dis Child Education Practice. 2015; 100: 13-18. PMid:24890926 https://doi.org/10.1136/archdischild-2013-305193

[16] Mtshali N, Uys L, Kamanzi D, et al. The Adherence of Five Nursing Schools in Africa to Regional Educational Standards: An Evaluation Report. Africa Journal of Nursing and Midwifery. 2007; 9(1): 3-21.

[17] Browning M, Pront L. Supporting nursing student supervision: An assessment of an innovative approach to supervisor support. Nurse Education Today. 2015; 35(6): 740-745. PMid:25769729 https ://doi.org/10.1016/j.nedt.2015.02.003

[18] Holmund K, Lindgren B, Athlin E. Group supervision for nursing students during their clinical placements: its content and meaning. Journal of Nursing Management. 2010; 18(6): 678-688. PMid:20840362 https://doi.org/10.1111/j.1365-2834.2010.01157.x

[19] Lindquist I, Johansson I, Severinsson E. Evaluation of Process oriented supervision of students. Nursing Health Sciences. 2012; 14(1): 2-7. PMid:21827585 https://doi.org/10.1111/j.1442-201 8.2011.00628.x

[20] Stevens KR. Impact of evidence based practice in Nursing and next big idea. The online Journal of Issues in Nursing. 2013; 18(2) Available from: http://nursingworld.org/MainMenuCategor ies/ANAMarketplace/ANAPeriodicals/0JIN/TableofCont ents/Vol18-2013/No2-May-2013/Impact-of-Evidence-B ased-Practice.html
[21] Nazik MAZ, Hanadi YH, Olfat S. Developing and Understanding of research based nursing pedagogy among clinical instructors: A qualitative Study. Nurse Education Today. 2014; 34(11): 1352-1356.

[22] Majid S, Foo S, Luyt B, et al. Adopting evidence-based practice in clinical decision making: nurses' perceptions, knowledge, and barriers. Journal of Medical Library Association. 2011; 99(3): 229-236.

[23] Delaney L, Sainsbury K. Clinical Engagement Model: Providing the Support between Students and the Clinical Environment. Australia Nursing and Midwifery Journal. 2016; 24(4): 32-32.

[24] Jasson I, Ene KW. Nursing students' evaluation of quality indicators during learning in clinical practice. Nursing Education Practice. 2016; 20: 17-22. PMid:27428799 https ://doi.org/10.1016/j nepr.2016.06.002

[25] Law YA, Chan EA. Taken-for-granted assumptions about the clinical experience of newly graduated registered nurses from their preregistration paid employment: A narrative inquiry. Nurse Education Practice. 2016; 20: 1-10. PMid:27428797 https ://doi.org/10 $.1016 / j$.nepr. 2016.06.001

[26] Carlson E, Idvall E. Nursing students' experiences of the clinical learning environment in nursing homes: A questionnaire study using the CLES+T evaluation scale. Nurse Education Today. 2014; 34(7): 1130-1134. PMid:24529997 https ://doi.org/10.1016/ j.nedt. 2014.01.009

[27] Biachi M, Bressan V, Cadorin L, et al. Patient safety competencies in undergraduate nursing students: a rapid evidence assessment. Journal of Advanced Nursing. 2016; 72(12): 2966-2979. PMid:27222204 https ://doi.org/10.1111/jan.13033

[28] Hirst SP. Nursing Students on the Unit. Journal of Gerontological Nursing. 2016; 42(8): 4-6. PMid:27468174 https://doi.org/10 .3928/00989134-20160713-01

[29] Kristofferzon M, Mårtensson G, Mamhidir A, et al. Nursing students' perceptions of clinical supervision: The contributions of preceptors, head preceptors and clinical lecturers. Nurse Education Today. 2016; 33(10): 1252-1257.

[30] Bowers HF. Designing quality course management systems that foster intra-professional education. Nurse Education in Practice. 2006; 6(6): 418-423. Available from: http: //login.ezproxy.library.ualberta.ca/login?url=http: //search.ebscohost.com.login.ezproxy.library.ualbe rta. ca/logi. aspx?direct=true\&db=rzh\&AN=2009622696 \&site=ehost - live\&scope=site

[31] Bell SA, Rominski S, Bam V, et al. An Analysis of Nursing Education in Ghana: Priorities for Scaling-up the Nursing Workforce. Nursing Health Sciences. 2013; 15(2): 244-249.

[32] Bandali K, Parker K, Mummery M, et al. Skills integration in a simulated and interprofessional environment: an innovative undergraduate applied health curriculum. Journal of Interprofessional Care. 2008; 22(2): 179-189. Available from: http://login.ezproxy.library.ualberta.ca/login?ur l=http: //search.ebscohost. com.login.ezproxy.library . ualberta. $c a /$ login. aspx?direct =true\&db=rzh\&AN=2009 $853601 \&$ site=ehost -1 ive\&s cope $=$ site

[33] Chau J, Denomme J, Murray J, et al. Inter-professional education in the acute-care setting: the clinical instructor's point of view. Physiotherapy Canada. 2011; 63(1): 65-75. PMid:22210981 https ://doi .org/10.3138/ptc. 2009-41

[34] Melnyk BM, Davidson S. Creating a Culture of Innovation in Nursing Education Through Shared Vision, Leadership, Interdisciplinary Partnerships, and Positive Deviance. Nursing Administration Quarterly. 2009; 33(4): 288-295. PMid:19893441 https: //doi.org/10.1097/NAQ.0b013e3181b9dcf8 